\title{
Analysis on Pollution Factors of Urban River
}

\author{
Zhiyi Lei \\ College of Harbour, Coastal and Offshore Engineering, Hohai University, Nanjing, China \\ Email: leizhiyi@hhu.edu.cn
}

Received October 2015

\begin{abstract}
Main pollutants of the urban scenic river in Nanjing City are studied in this paper. In the study area a total of 39 monitoring points are set in natural water, around pumping stations and near the tail water of sewage treatment plant. Through the monitoring of pollution sources of receiving conventional index, the pollution sources distribution and river pollution factors are detailed analyzed, as nutrient salts, heavy metals, and environmental endocrine disruptors. And sources of the pollution factors are analyzed by principal component analysis to get the main pollution factors in this channel.
\end{abstract}

\section{Keywords}

\section{Source Apportionment, Distribution, Water Environment, Principal Component Analysis}

\section{Introduction}

At present, city river catchment comes mainly from tail water of wastewater treatment plant, straight row of sewage, and the upstream catchment [1] [2]. Besides conventional pollutants, the catchment water also contains toxic and harmful pollutants, including detergent, pathogenic microorganism, chlorination by-product, endocrine disruptors, high concentration heavy metal and pesticide etc. [3] [4].

A large number of epidemiological data showed that, environmental endocrine disruptors (environmental endocrine disruptors/endocrine disrupting chemicals, ECDs) can cause reproductive disorders, birth defects, developmental abnormalities, metabolic disorders and certain cancers, and is a major risk factor for the water environment in the world [5] [6]. The endocrine disrupting chemicals in sewage are often detected with polycyclic aromatic hydrocarbons (PAHs), phthalic acid esters (two PAEs), phenols, organic chlorine pesticides (OCPs), polychlorinated biphenyls (polychilodnated-bipheneyls, referred to as PCBs) and two phenyl ketones [7]. Among them, the adjacent benzene two formic acid esters, PAHs, PCBs are detected in the city river [8] [9].

\section{Distribution of the Pollution Factors in Urban River}

\subsection{Measuring Points}

According to the analysis of the characteristics of water environment and investigation of pollution sources in the Qinhuai River, in the study area a total of 39 monitoring points are set for water quality monitoring, among them there are 24 points in natural water, 11 points around pumping station, and 4 points in the tail water of sewage treatment plant (Figure 1). 


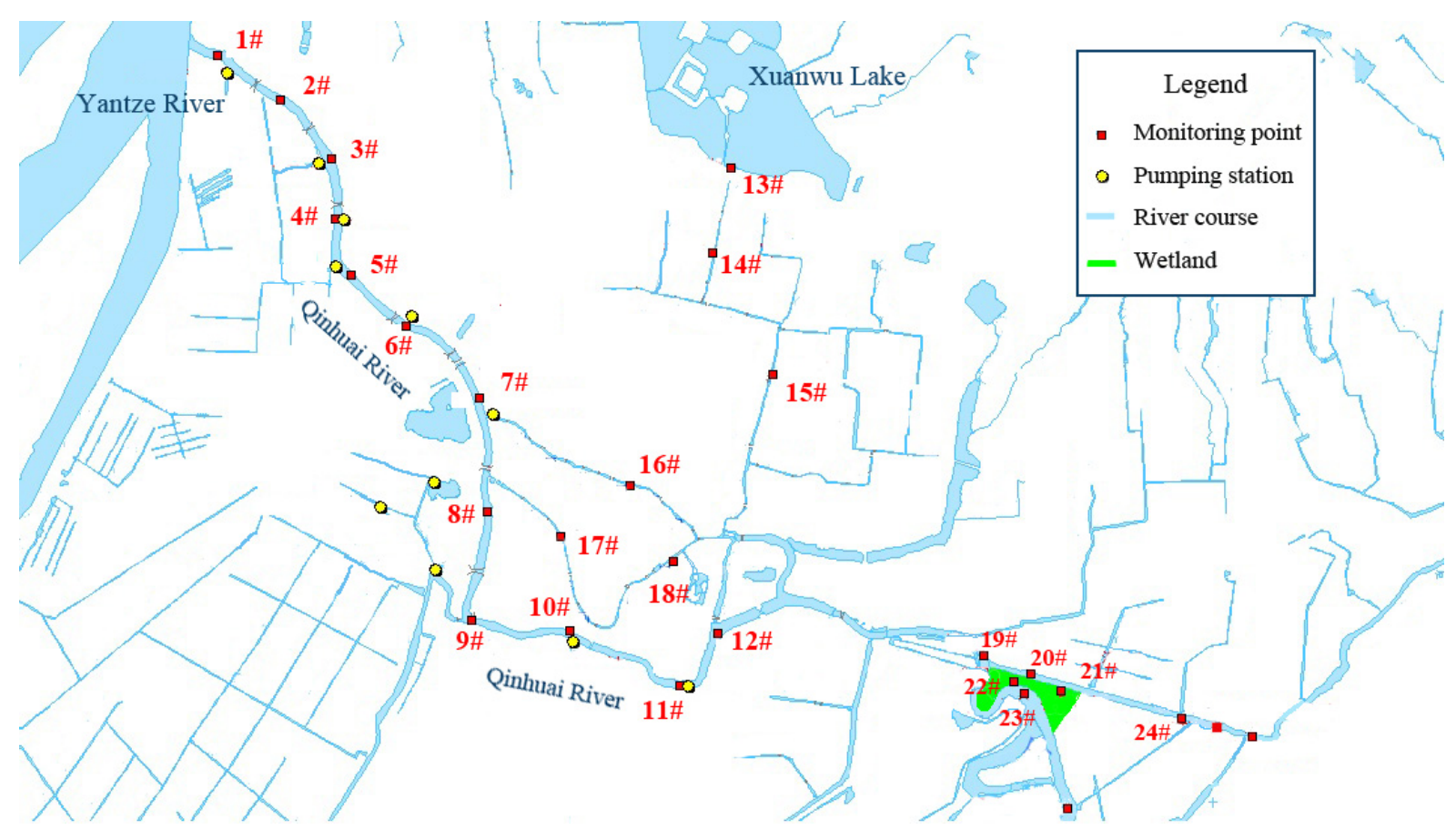

Figure 1. Distribution of monitoring points.

Detection of indicators includes the general physical and chemical indicators, eutrophication and nutrient index, health index, toxicology indicators (including heavy metals, endocrine disrupting chemicals etc.).

\subsection{Characteristics and Sources of Heavy Metals}

Distribution of heavy metals in natural waters is shown in Figure 2. It can be seen, as is ranking in natural waters: the Yunliang River > the WaiQinhuai River > the NeiQinhuai River; Sequencing of $Z n$ content is the Yunliang River > the Qinhuai River > the Qinhuai River, and is the same as the sort of $P b$ content, $C d$ content and Mn content. The content of $\mathrm{Cr}$ and $\mathrm{Cu}$ distribute evenly; sorting the $\mathrm{Fe}$ content is the WaiQinhuai River > the NeiQinhuai River $>$ the Yunliang river.

The distribution of heavy metal content in pollution source is shown in Figure 3. The heavy metal content in Yunliang River is $\mathrm{Zn}>\mathrm{Pb}>\mathrm{As}>\mathrm{Cd}>\mathrm{Mn}>\mathrm{Cr}>\mathrm{Cu}=\mathrm{Fe}$, in which the content of $\mathrm{Zn}$ is the highest of 1878 $\mathrm{mg} / \mathrm{L}$; the content in upstream of Qinhuai River is $\mathrm{Zn}>\mathrm{Pb}>\mathrm{As}>\mathrm{Fe}>\mathrm{Mn}>\mathrm{Cd}=\mathrm{Cr}>\mathrm{Cu}$, and $\mathrm{Pb}>\mathrm{As}>\mathrm{Fe}>$ $\mathrm{Zn}>\mathrm{Mn}>\mathrm{Cd}>\mathrm{Cr}=\mathrm{Cu}$ in Qingjiangqiao; and $\mathrm{Pb}>\mathrm{As}>\mathrm{Fe}>\mathrm{Zn}>\mathrm{Mn}>\mathrm{Cd}>\mathrm{Cr}=\mathrm{Cu}$ in Xiaodoumen; and $\mathrm{Pb}>\mathrm{As}>\mathrm{Fe}>\mathrm{Zn}>\mathrm{Mn}=\mathrm{Cd}=\mathrm{Cr}>\mathrm{Cu}$ in Shitoucheng; and $\mathrm{Pb}>\mathrm{As}>\mathrm{Fe}>\mathrm{Mn}>\mathrm{Zn}>\mathrm{Cr}>\mathrm{Cd}=\mathrm{Cu}$ in Tiechuangleng; $\mathrm{Pb}>\mathrm{As}>\mathrm{Zn}>\mathrm{Fe}>\mathrm{Mn}=\mathrm{Cr}>\mathrm{Cd}>\mathrm{Cu}$ in South Yudai River; $\mathrm{Pb}>\mathrm{As}>\mathrm{Fe}=\mathrm{Cr}>\mathrm{Mn}=\mathrm{Zn}=$ $\mathrm{Cd}>\mathrm{Cu}$ in Qingliangmen; $\mathrm{Zn}>\mathrm{Pb}>\mathrm{As}>\mathrm{Cd}>\mathrm{Mn}>\mathrm{Cr}>\mathrm{Cu}>\mathrm{Fe}$ in Chengdong Sewage plant.

\subsection{Distribution of Endocrine Disruptors}

Phthalate esters (PAEs). The distribution of phthalic esters in natural water is shown in Figure 4. Thus it can be seen, that the contents of $\sum$ PAEs in natural water is the WaiQinhuai River $>$ the NeiQinhuai River $>$ the Yunliang River $>$ the city lakes. The average contribution rate of 15 PAEs concentration is DiBP $>$ DEEP $>$ DMP $>$ DBP $>$ DEP $>$ DOP $>$ DMEP $>$ BBP $>$ DBEP $>$ DCHP $>$ DPP $>$ DHP $>$ DEHP $>$ BMPP $>$ DINP. The concentration range of $\sum$ PAEs is $108.04 \mathrm{ng} / \mathrm{L}-1121.82 \mathrm{ng} / \mathrm{L}$ with the highest point in the Fengtai bridge (7\#), followed by $5 \#$ and the Shangfu bridge, the concentrations of $1070.42 \mathrm{ng} / \mathrm{L}$ and $1023.94 \mathrm{ng} / \mathrm{L}$.

The distribution of phthalate esters content in pollution source is shown in Figure 5. The content sequence is Qinjiang Bridge $>$ Shitoucheng $>$ Tiechuangleng $>$ Xiaodoumen $>$ Qingliangmen $>$ Yunliang River $>$ South YudaiRiver $>$ Jingxinzhou $>$ Chengdong sewage plant $>$ Xianlin sewage plant $>$ upstream of QinhuaiRiver $>$ Chengbei sewage plant. $\sum P A E s$ concentration ranges from $92.68 \mathrm{ng} / \mathrm{L}$ to $2698.50 \mathrm{ng} / \mathrm{L}$ with the main factor of DMP, DEP, DiBP, DBP and BBP. 


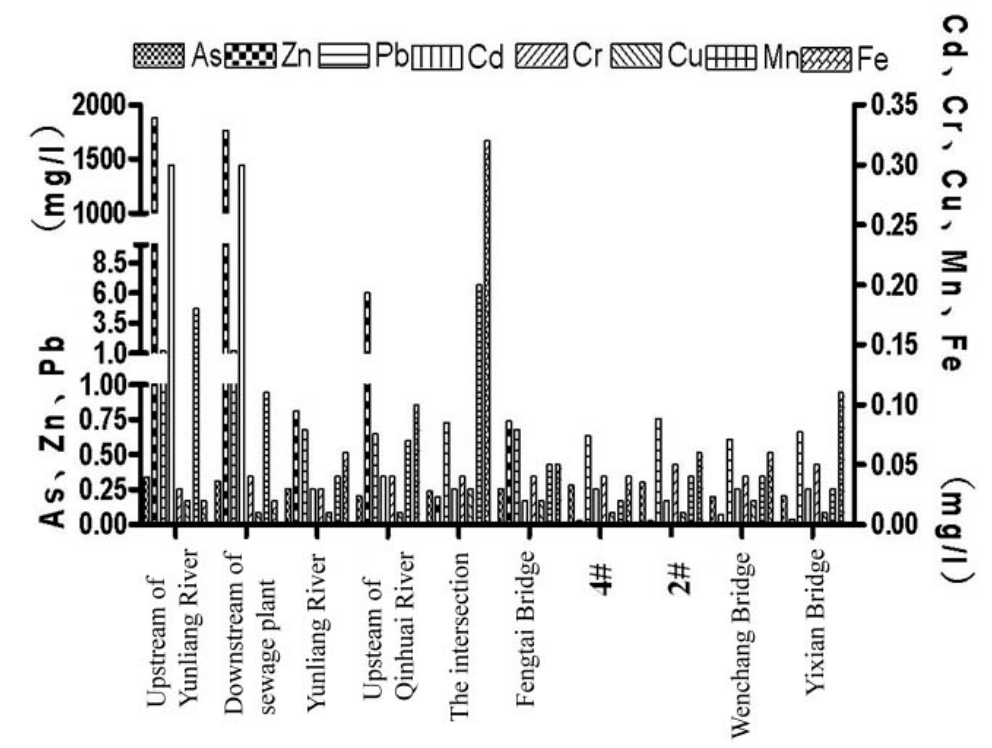

Figure 2. Distribution of heavy metal in natural water.

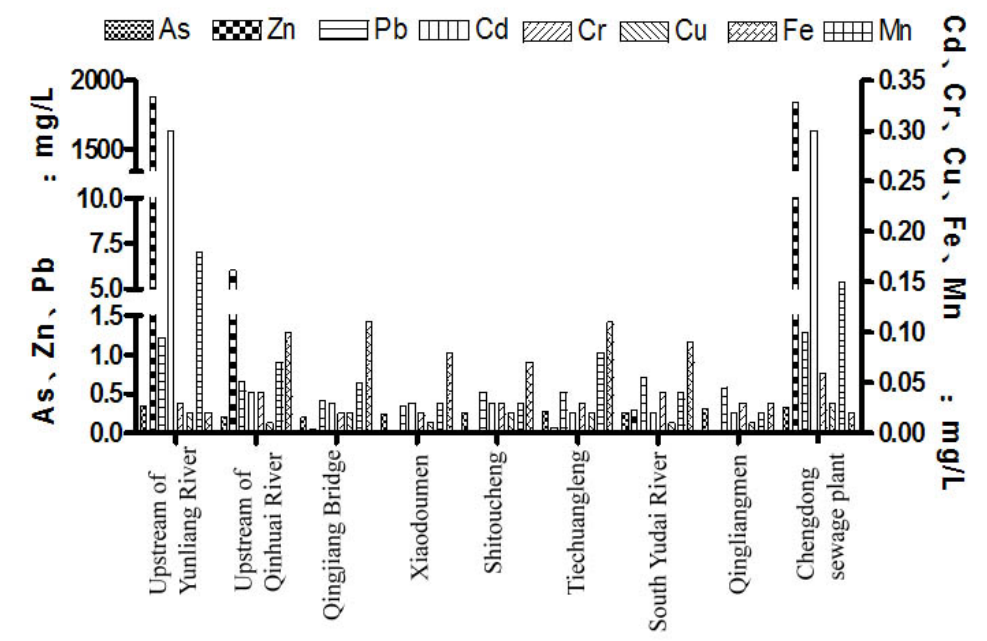

Figure 3. Distribution of heavy metal in pollutant source.

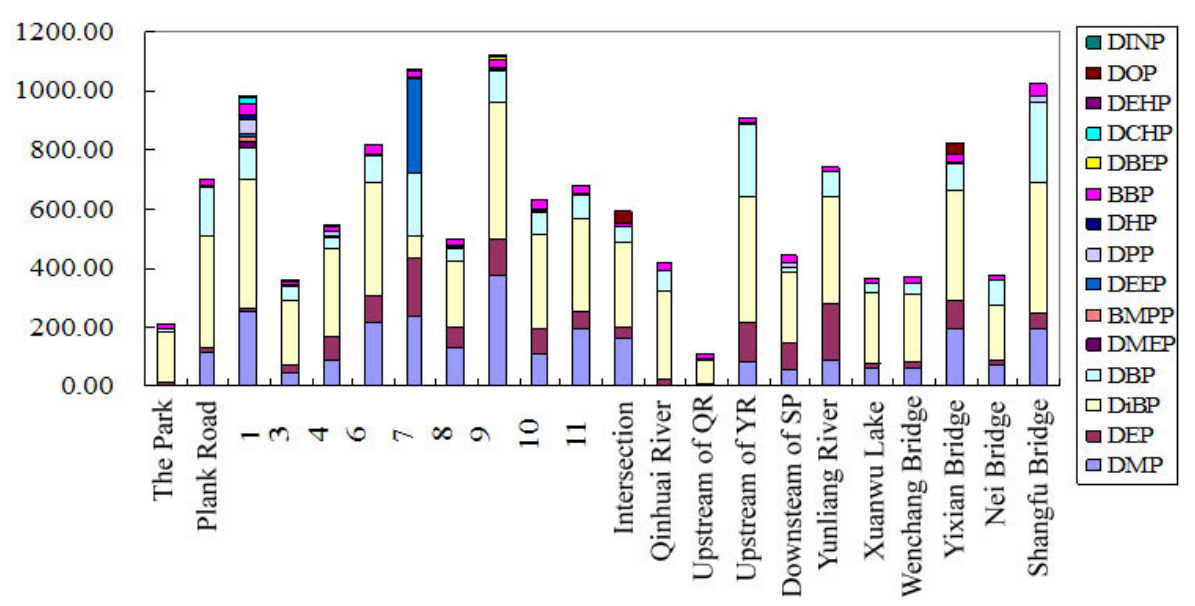

Figure 4. Distribution of PAEs in natural water (ng/L). 


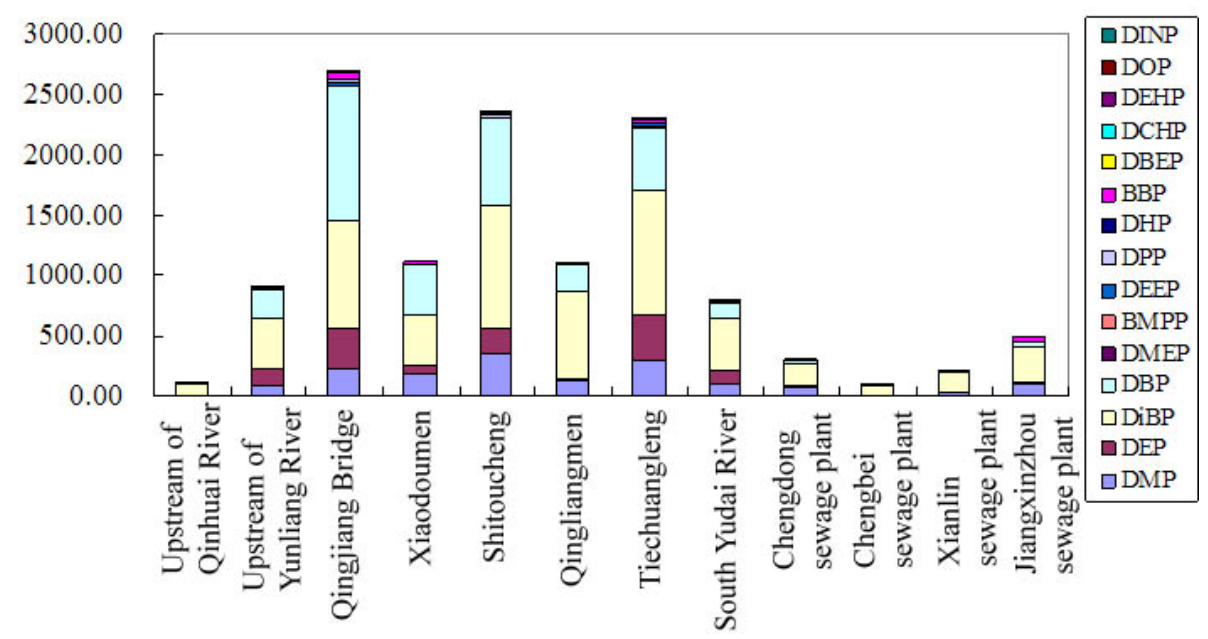

Figure 5. Distribution of PAEs in pollutant source (ng/L).

Polychlorinated biphenyls (PCBs). The distribution of PCBs in natural water is shown in Figure 6. It's clearly that the contents of $\sum P C B s$ in natural waters is the NeiQinhuai River $>$ the Yunliang River $>$ the WaiQinhuai River $>$ the city lakes. The average contribution rate of 7 PCBs concentration is PCB52 > PCB180 > PCB101 > PCB118 > PCB153 > PCB138 > PCB28. $\sum$ PCBs concentration ranges from $2.66 \mathrm{ng} / \mathrm{L}$ to 474.30 ng/L with the highest point in the Shangfu Bridge, followed by the downstream of sewage treatment plant and point $1 \#$, the concentrations of $290.01 \mathrm{ng} / \mathrm{L}$ and $252.04 \mathrm{ng} / \mathrm{L}$.

The distribution of PCBs in pollutant source is shown in Figure 7. It's clearly that the contents of $\sum$ PCBs is Qingjiang bridge $>$ Tiechuangleng $>$ upstream of Yunliang River $>$ South Yudai River $>$ Xiaodoumen $>$ Shitoucheng > Jiangxinzhou sewage plant $>$ Qingliangmen $>$ Chengdong sewage plant $>$ Upstream of Qinhuai River $>$ Chengbei sewage plant $>$ Xianlin sewage plant. $\sum$ PCBs concentration ranges from $1.04 \mathrm{ng} / \mathrm{L}$ to $614.42 \mathrm{ng} / \mathrm{L}$ with the main factor of PCB52, PCB118 and PCB180.

Polycyclic aromatic hydrocarbon (PAH). The distribution of PCBs in natural water is shown in Figure 8. It's clearly that the contents of $\sum P A H s$ in natural waters is the WaiQinhuai River $>$ the NeiQinhuai River $>$ the Yunliang River $>$ the city lakes. The average contribution rate of 16 PAHs concentration is Naphthalene $>$ Acenaphthene (Ace) $>$ Phenanthrene $>$ Fluorene $>$ Indeno [1,2,3-cd] pyrene $(\mathrm{InP})>$ Benzo [b] fluoranthene $(\mathrm{BbF})>$ Acenaphthene $>$ Benzo [a] anthracene $(\mathrm{BaA})>$ Two benzo $[\mathrm{a}, \mathrm{H}]$ anthracene $>$ Fluoranthene $>$ Pyrene $>$ Chrysene $(\mathrm{Chr})>$ Benzo[g,h,i]perylene $(\mathrm{BPR})>$ Benzo [k] fluoranthene $(\mathrm{BkF})>$ Benzo[a]pyrene $(\mathrm{BaP})>$ Anthracene (ANT). $\sum P A H s$ concentration ranges from $16.93 \mathrm{ng} / \mathrm{L}$ to $455.95 \mathrm{ng} / \mathrm{L}$ with the highest point in the Fengtai bridge, followed by point $1 \#$ and $5 \#$, the concentrations of $226.24 \mathrm{ng} / \mathrm{L}$ and $220.70 \mathrm{ng} / \mathrm{L}$.

The distribution of PCBs in pollutant source is shown in Figure 9. It's clearly that the contents of $\sum P A H s$ is Tiechuangleng $>$ Qingjiangqiao $>$ Shitoucheng $>$ Upsteam of Yunliang River $>$ Qingliangmen $>$ Xiaodoumen $>$ Chengdong sewage plant $>$ South Yudai River $>$ Jiangxinzhou $>$ Xianlin sewage plant $>$ Upsteam of Qinhuai River > Chengbei sewage plant. $\sum P A H s$ concentration ranges from $11.90 \mathrm{ng} / \mathrm{L}$ to $1064.68 \mathrm{ng} / \mathrm{L}$ with fluoranthene,the main factor of naphthalene, Ace, fluorine, phenanthrene, BaA, BbF and InP.

From the comparison of heavy metal and environmental endocrine disruptors in different types of natural water and the pollution source, we can get that there are different concentration of $\mathrm{Zn}, \mathrm{Pb}, \mathrm{As}, \mathrm{Fe}, \mathrm{Mn}, \mathrm{Cd}, \mathrm{Cr}$ and $\mathrm{Cu}$ in natural water and pollution source, in which the main characteristic factors in upstream and tail-water of sewage plant; The main phthalic acid esters in studied natural waters are DMP, DEP, DiBP, DBP, BMPP, DPP, BBP, DCHP, DEHP. And the concentrations of DMP, DiBP and DBP are higher. PCB52, PCB180 are mainly in natural water, and the concentrations are higher in upstream and storm runoff.

The PAHs in natural water conclude of naphthalene, Acenaphthene (Ace), phenanthrene, fluorine, Indeno (1,2,3-cd) pyrene (InP), Benzo (b) fluoranthene (BbF), acenaphthene, Benzo[a] anthracene (BaA),Two benzo (a, $\mathrm{H})$ anthracene, fluoranthene, pyrene, chrysene (Chr), benzo[g,h,i]perylene (BPR), benzo(k) fluoranthene (BkF), benzo[a]pyrene (BaP), anthracene(ANT). The concentration of naphthalene, fluorene, $\mathrm{BaA}, \mathrm{BaP}$ and InP are higher in upstream water, and those of naphthalene, acenaphthene, fluorene, $\mathrm{BaP}$ and $\mathrm{InP}$ are higher in storm runoff. 


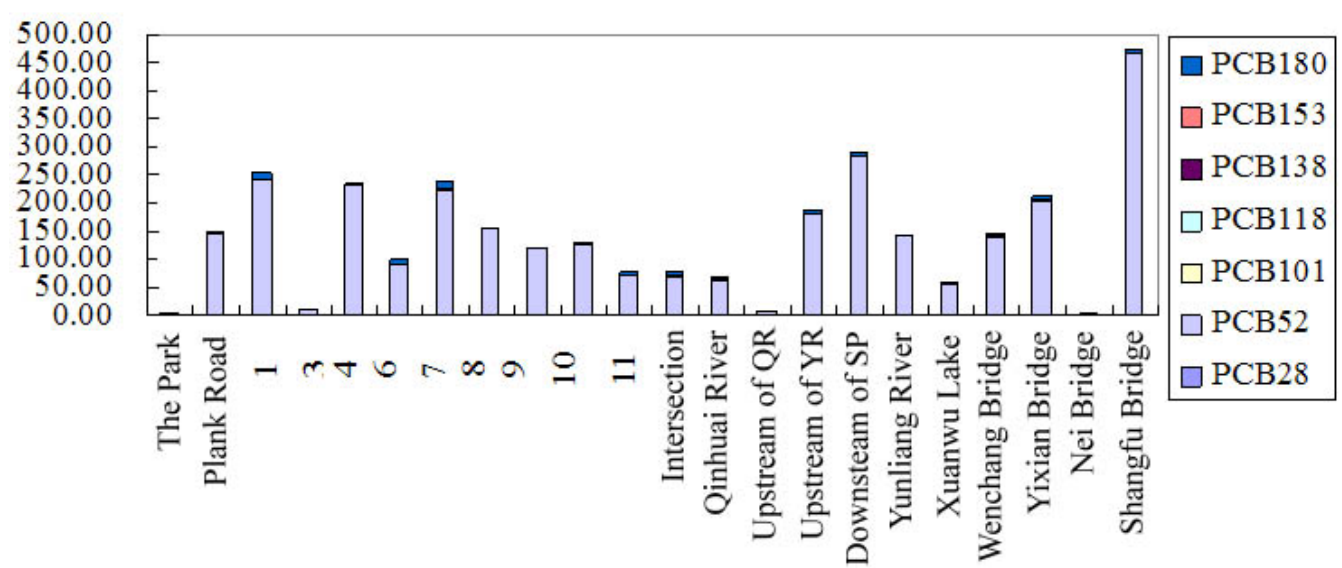

Figure 6. Distribution of PCBs in natural water (ng/L).

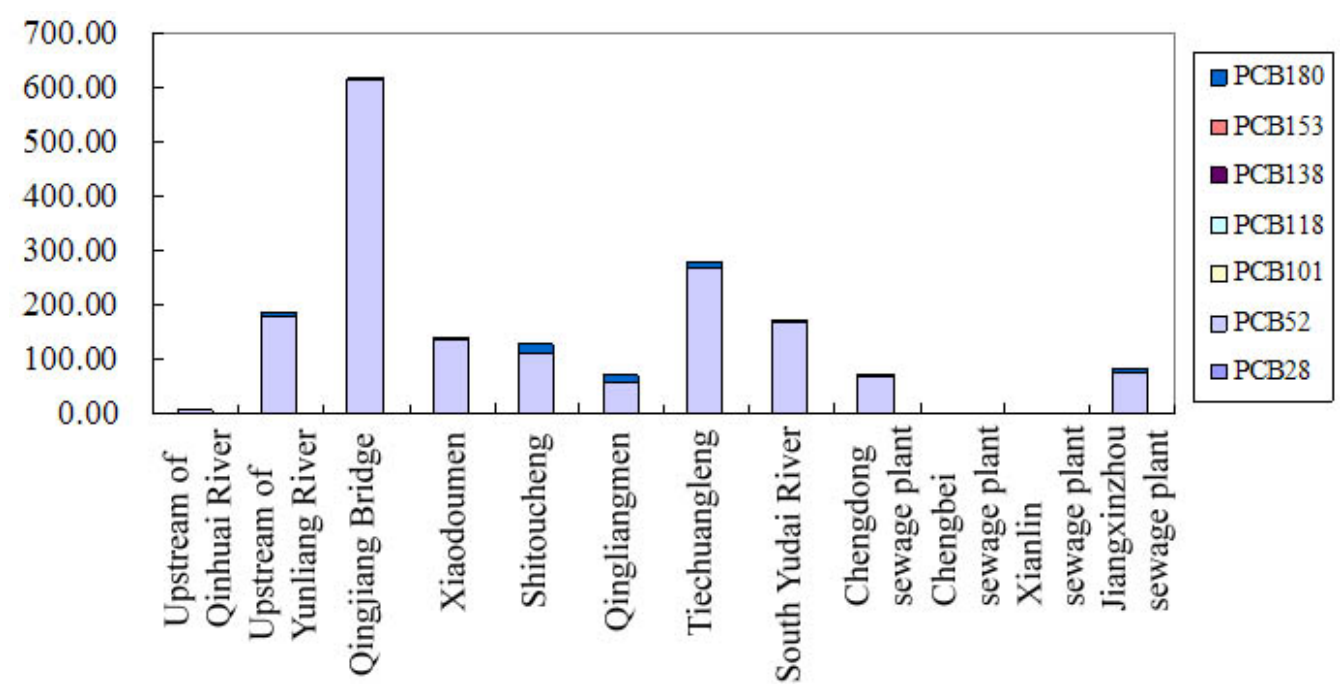

Figure 7. Distribution of PCBs in pollutant source (ng/L).

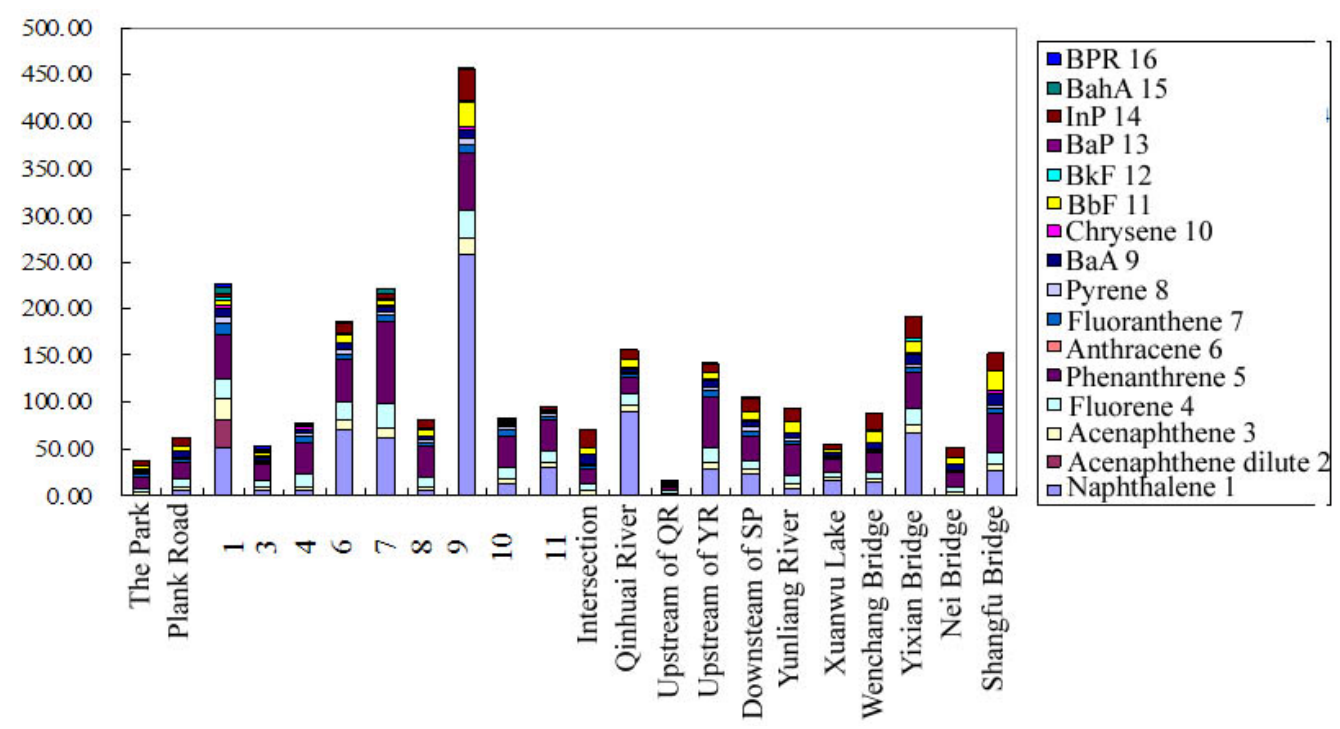

Figure 8. Distribution of PAHs in natural water (ng/L). 


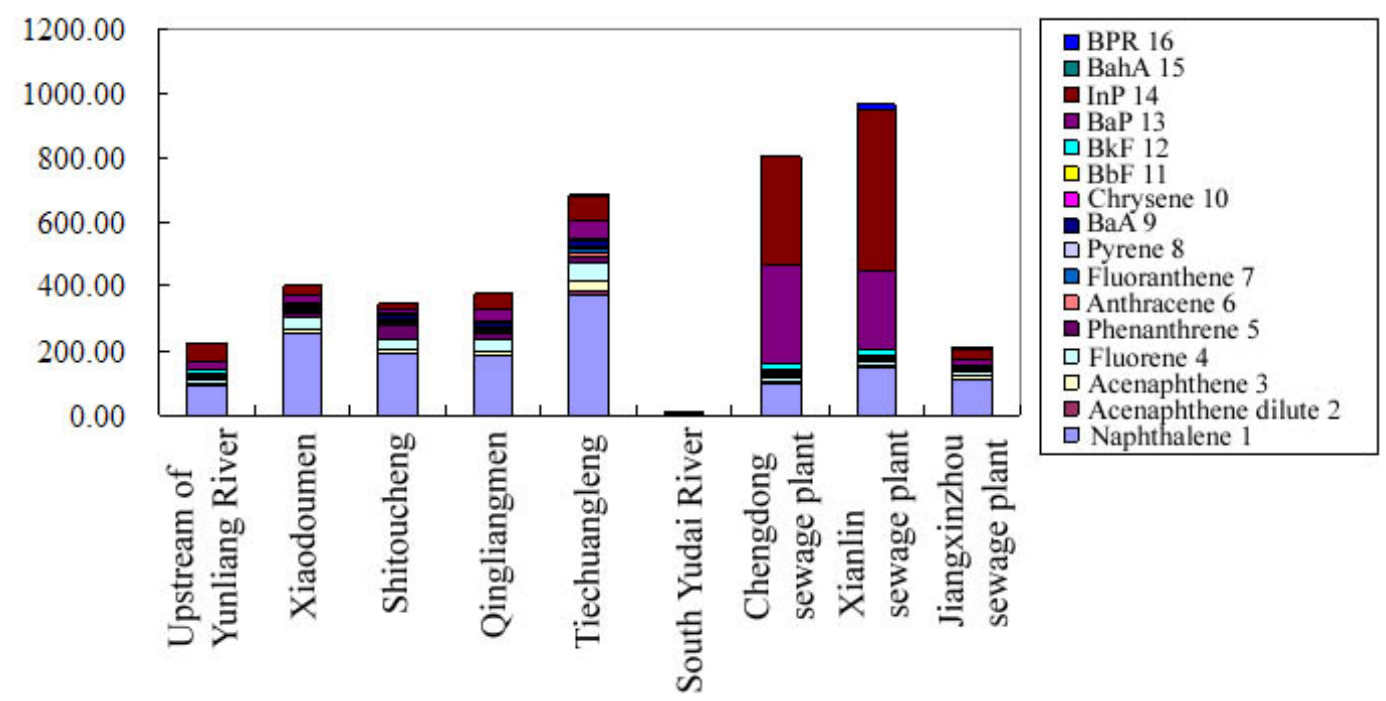

Figure 9. Distribution of PAHs in pollutant source (ng/L).

\section{Source Apportionment of Pollution Factors}

\subsection{Principal Component Analysis of Water Quality}

Using SPSS13.0, select C, N, S and P, some hygiene factors and main risk factor to be statistical analyzed. Based on the rule of cumulative variance of principal component number should be more than $70 \%$, the maximal variance rotation method (Varimax), select the factors whose load is greater than 0.6. Thus the results are the $\mathrm{KMO}$ value is 0.760 , Bartlett's sphericity is 563.89 , and concomitant probability is 0 , so that the use of principal component analysis method is feasible.

The eigenvalue and contribution rate of principal component analysis are shown in Table 1, in which the four factors can reflect $71.07 \%$ of total information.

Table 1 shows that the contribution rate of the first principal component feature, F1, is $22.74 \%$, associated with the index of BMPP, DPP, BBP, DiBP, acenaphthene, pyrene, fluoranthene, phenanthrene, flexion. It mainly reflects the pollution status of macromolecular phthalate esters and small molecules of PAHS.

The contribution rate of the second principal component feature, F2, is $21.91 \%$, associated with $\mathrm{NH}_{4}^{+}-\mathrm{N}$, TN, TOC, DBP, DEP. It mainly reflects the population status of the nutrient salts, organic pollution and macromolecular of PAES.

The contribution rate of the third principal component feature, F3, is $14.69 \%$, associated with naphthalene, $\mathrm{BaF}, \mathrm{BbF}$, InP. It mainly reflects the population status of the macromolecular of PAHS.

The contribution rate of the forth principal component feature, F4, is $11.73 \%$, associated with nitrite, nitrate, sulfate and fecal coliform bacteria. It mainly reflects the population status of inorganic toxicology indicators and health indicators.

\subsection{Principal Component Analysis of Pollutant Source}

The method and rules are the same to the analysis of water quality. Thus the results are the KMO value is 0.773 , Bartlett's sphericity is 500.01 , concomitant probability is 0 , so that the use of principal component analysis method is feasible.

The eigenvalue and contribution rate of principal component analysis are shown in Table 2, in which the three factors can reflect $72.58 \%$ of total information.

Table 2 shows the main components in pollutant source are PAHs, polychlorinated biphenyls (PCB52, PCB180), PAEs (BMPP, DPP, DEP, DBP, DMP, DiBP), TOC, TN, $\mathrm{SO}_{4}^{2-}$, fecal coliform bacteria. Principal component analysis results shows that the main pollution group and water quality have a good corresponding relationship. 
Table 1. Characteristic value and contribution rate.

\begin{tabular}{cccc}
\hline & Characteristic Value & Contribution Rate (\%) & Cumulative Contribution Rate (\%) \\
\hline F1 & 6.821 & 22.74 & 22.74 \\
F2 & 6.574 & 21.91 & 44.65 \\
F3 & 4.407 & 14.69 & 59.34 \\
F4 & 3.520 & 11.73 & 71.07 \\
\hline
\end{tabular}

Table 2. Characteristic value and contribution rate in pollutant source.

\begin{tabular}{cccc}
\hline & Characteristic Value & Contribution Rate (\%) & Cumulative Contribution Rate (\%) \\
\hline F1 & 10.297 & 34.33 & 34.33 \\
F2 & 7.491 & 24.97 & 59.29 \\
F3 & 3.986 & 13.29 & 72.58 \\
\hline
\end{tabular}

\section{Conclusions}

Heavy metal, PAEs, PCBs and PAHs are all detected. Factor with relevance ratio higher than 0.5 are $\mathrm{Zn}, \mathrm{Pb}$, As, Cd, Cr, Cu, DMP, DEP, DiBP, DBP, BMPP, DPP, BBP, DCHP, DEHP, PCB52, PCB101, PCB118, PCB153, PCB180, naphthalene, Ace, phenanthrene, fluorine, ANT, pyrene, fluoranthene, BaA, Chr, BbF, BaP, InP, Benzo(ghi)perylene .

Sources of pollution in the study area includes forebay sewage of pumping station, storm runoff, tail water of sewage plant and the water upstream. Among them, the indicators are very serious in forebay sewage, the concentrations of nitrite, nitrate and sulfate are higher in the tail water of sewage plant, and the concentration of nitrate nitrogen is higher in the upstream water.

The main pollution group and water quality have a good corresponding relationship. The main pollution factors with potential sources are PAHs, PAEs, TN, $\mathrm{NH}_{4}^{+}-\mathrm{N}, \mathrm{TOC}, \mathrm{SO}_{4}^{2-}$ and fecal coliforms.

\section{Acknowledgements}

This research is financially supported by the National Natural Science Foundation of China, Grant No. 51409088.

\section{References}

[1] Smith, S.V., Renwick, W.H., et al. (2012) Distribution and Significance of Small, Artificial Water Bodies across the United States Landscape. The Science of the Total Environment, 21-30.

[2] WHO (2010) Guidelines for Safe Recreational Water Environments, Volume 2: Swimming Pools and Similar Environments.

[3] Hermann, F., Thomas, K., Thomas, O., et al. (2002) Occurrence of Phthalate and Bisphenol A and F in the Environment. Water Research, 1429-1438.

[4] Zhao, X.K., Yang, G.P. and Wang, Y.J. (2004) Adsorption of Diethyl Phthalate on Marine Sediments. Water Air and Soil Pollution, 157, 179-192. http://dx.doi.org/10.1023/B:WATE.0000038880.57430.c3

[5] Mitra, S., Dellapenna, T.M., Dickhut, R.M., et al. (2009) Polycyclic Aromatic Hydrocarbons Distribution within Lower Hudson River Estuary Sediments: Physical Mixing vs Sediment Geochemistry. Estuarine, Coastal and Shelf Science, 311-326.

[6] Rosa, M.V., Fernandez, P., Martinez, C., et al. (2010) Polycyclic Aromatic Hydrocarbons in Remote Mountain Lake Waters. Water Research, 3916-3926.

[7] Mitra, S. and Bianchi, T.S. (2003) A Preliminary Assessment of Polycyclic Aromatic Hydrocarbon Distributions in the Lower Mississippi River and Gulf of Mexico. Marine Chemistry, 273-288. http://dx.doi.org/10.1016/S0304-4203(03)00074-4 
[8] Chen, Y.Y., Zhu, L.Z. and Zhou, R.B. (2006) Characterization and Distribution of Polycyclic Aromatic Hydrocarbon in Surface Water and Sediment from Qiantang River, China. Journal of Hazardous Materials, 311-326.

[9] Bremle, G. and Larsson, P. (1998) PCBs in River Ema Ecosystem. Human and Environment Magazine, 27, $384-391$. 